Result Vocal effort was associated to school degree, showing an increasing at the primary school where the pupils are noisier. A significant association was found between the sound level evaluated $15 \mathrm{~cm}$ from the speaker's mouth and the noise level (coefficient $=1.45, \mathrm{p}$ value $=0.016$ ). Multivariate linear regression models explained the sound pressure level emitted by the speaker (SPL) by phonation percentage and reverberation time. Average reverberation times at $1 \mathrm{kHz}$ were 0.8 and $2.3 \mathrm{~s}$, while average STI, evaluated by a theoretical model, were approximately 0.6 (sufficient) and 0.4 (poor), in treated and untreated classrooms, respectively. In untreated classrooms the SPL was on average 30\% higher $(\mathrm{p}=0.041)$.

Discussion The high phonatory load of teaching is significantly worsened by the classroom inadequate acoustic parameters. Long reverberation times and, consequently, poor speech intelligibility, high noise levels and vocal effort are significantly related. Improved acoustic design of the classrooms would reduce the risk for vocal apparatus pathologies.

\section{HEALTHIER WORKERS, HAPPIER WORKERS' PROGRAMME: A PERSON-CENTRIC APPROACH TO APPROACHING HEALTH \& SAFETY AT THE WORKPLACE FOR BUS-DRIVERS IN SINGAPORE}

${ }^{1}$ CHNG Jocelyn, ${ }^{2}$ Sim Beng Khoon. 'Senior Assistant Director (Total Workplace Safety and Health), Workplace Safety and Health Council (Singapore), Tripartite Alliance Limited; ${ }^{2}$ Director (Workplace Health and Outreach Division), Health Promotion Board, Ministry of Health (Singapore)

\subsection{6/oemed-2018-ICOHabstracts. 1462}

Introduction 54\% of Singapore's workforce are 40 years and above. Keeping this ageing population safe and healthy is crucial. As part of Singapore's Action Plan for Successful Ageing, we focused on sectors with a higher prevalence of lowerincome mature workers with limited access to healthcare. They have low to moderate health literacy and fare poorer in health. Their unstructured workplaces with multiple shift patterns make it difficult for them to participate in structured programmes. One of our priorities is the transport sector. Using a person-centric approach, we aimed to impact bus drivers by understanding their needs and addressing both ageand work-related issues through a customised programme brought to their doorstep.

Methods 2114 bus drivers from 2 market leaders were recruited. The holistic programme comprised:

i. Onsite 9 month Health Intervention Programme $(n=1,114)$ Basic profiling showed higher disease rates. Fasting blood Chronic Disease Health Screening was conducted at 4 am at depots with a lifestyle survey. Using the results, bus drivers received monthly group health coaching at interchanges, where they build practical skills to manage chronic disease $\&$ bodily pain, and other OSH issues like glare. 8 months later, a post screening was conducted to track improvements.

ii. Workplace Risk Assessment $(n=1,000)$ conducted by $\mathrm{OH}$ specialists over 3 phases: risk identification, evaluation $\&$ management. This involved evaluating occupational hazards at depots, interchanges and within bus cabins, assessing actual driving, surveys on ergonomics \& fatigue and focus groups with supervisors \& staff. iii. Mental Wellbeing Training-90\% of supervisors trained to pick up mental wellbeing issues in staff and make suitable referrals.

Results Our person-centric approach was well-received and results were encouraging. $\sim 50 \%$ of those with abnormal screening results improved in at least 1 chronic condition by post-screening. Significantly, 1 in 4 improved from abnormal to normal health status in 9 months. After Workplace Risk Assessment, short-term interventions like driving ergonomics training and sunglass issuance have been put in place. Longerterm recommendations for national policies have also been submitted.

Discussion We achieved impact by seeing issues through the bus drivers' lenses, working around operational schedules and challenging conventions. We were able to scale up quickly to impact all 10000 bus drivers in Singapore. Going forward, we will strengthen efforts to ensure sustainability.

\section{SAFETY MANAGEMENT SYSTEMS: PEER-TO-PEER RATINGS IN THE SHARING ECONOMY}

${ }^{1} \mathrm{E}$ MacEachen, ${ }^{1} \mathrm{E}$ Reid Musson, ${ }^{1} \mathrm{E}$ Bartel, ${ }^{1} \mathrm{~J}$ Carriere, ${ }^{1} \mathrm{SB}$ Meyer, ${ }^{1} \mathrm{~S}$ Varatharajan, ${ }^{2} \mathrm{~A}$ Kosny, ${ }^{1} \mathrm{P}$ Bigelow, ${ }^{2} \mathrm{R}$ Saunders. 'University of Waterloo, Waterloo, Canada; ${ }^{2}$ Institute for Work and Health, Toronto, Canada

\subsection{6/oemed-2018-ICOHabstracts. 1463}

Introduction To ensure the health and safety of workers, most jurisdictions have implemented workplace inspection and audit systems. This presentation examines OHS in the context of the growing 'sharing economy', taking the case of Uber ridesharing, who claim to keep self-employed drivers safe through measures including peer-to-peer ratings. We address the question: what is the Uber peer-topeer rating system and how does it work (or not) as part of an occupational health and safety system?

Method We conducted a critical interpretive study of ride sharing with Uber drivers, passengers and management, taxi managers and related policy makers in Ontario, Canada. Data include interviews and focus groups with 50 participants. These were recorded verbatim, coded and analysed using systematic strategies of constant comparison, consideration of deviant cases, and narrative analysis.

Results Despite Uber drivers being classified as 'self-employed' and Uber touting their ability to rate and choose their passengers, we find that drivers had few free choices. Drivers could not easily avoid undesirable passengers as they received app warnings that cancelled rides or non-pick up (despite passenger rating) could result in removal from the app. Driver ratings of passengers were tempered by having to rate them at ride end, before passengers 'rate drivers back'. To avoid low ratings by passengers, drivers rated them high. They also engaged in unsafe activities, including agreeing to carry excessive passengers and speeding. In addition, passenger ratings of drivers were idiosyncratic; low ratings of drivers sometimes reflected refusal to engage in unsafe activity.

Conclusion Peer-to-peer rating systems are created in complex circumstances of pressure from Uber and passengers. If drivers freely exercised their choice to decline unsafe rides, they could lose access to the Uber app and their income source. Overall, ratings were a source of stress for drivers and not an indicator of safety. 